\title{
ANALISIS SIKAP PEDULI LINGKUNGAN DAN MINAT BERWIRAUSAHA MAHASISWA PADA PERKULIAHAN PENGETAHUAN LINGKUNGAN
}

\author{
Fahmy Armanda ${ }^{1)}$ a), Wulandari Saputri ${ }^{2)}$ \\ ${ }^{1)}$ Pendidikan Biologi Fakultas Ilmu Tarbiyah dan Keguruan UIN Raden Fatah Palembang, \\ Jl. Prof. K.H. Zainal Abidin Fikri No. 1 A KM 3,5, Palembang 30126 \\ 2) Pendidikan Biologi Fakultas Keguruan dan Ilmu Pendidikan Universitas Muhammadiyah \\ Palembang, \\ Jl. Jendral Ahmad Yani 13 Ulu Seberang Ulu II, Kec. Plaju, Kota Palembang
}

a)fahmibio_uin@radenfatah.ac.id

Telp: +62-813-7047-6161

\begin{abstract}
Community in the $21^{\text {st }}$ was faced with a number of challenges, one of which was environmental problems and how to survive in the $21^{\text {st }}$ century. For this reason, there were two important things to be developed, namely an environmentally caring attitude and an interest in entrepreneurship. The development of both should be facilitated by lectures on Environmental Knowledge. This research is intended to analyze the environmental care attitude and interest in student entrepreneurship. The research method used was descriptive qualitative and data were collected through questionnaires and interviews. The results of this study are 1) The attitude of caring for the student's environment needs to be improved; 2) The interest in student entrepreneurship is very high so it needs to be facilitated through learning that invites students to practice the skills that have been taught. The results of this study are expected to be a foothold in how to develop learning to support the development of environmental awareness and interest in student entrepreneurship.
\end{abstract}

Key words: Environmental care attitude, entrepreneurship interest, learning model and strategy

\begin{abstract}
ABSTRAK
Pada abad 21 masyarakat dihadapkan pada beberapa tantangan, satu di antaranya adalah masalah lingkungan hidup dan bagaimana dapat bertahan hidup di abad 21. Untuk itu, terdapat dua hal yang penting dikembangkan, yakni sikap peduli lingkungan dan minat berwirausaha. Pengembangan keduanya seharusnya dapat difasilitasi oleh perkuliahan Pengetahuan Lingkungan. Penelitian ini ditujukan untuk menganalisis sikap peduli lingkungan dan minat berwirausaha mahasiswa. Metode penelitian yang digunakan adalah deskriptif kualitatif dan data dikumpulkan melalui penyebaran angket dan wawancara. Hasil dari penelitian ini adalah 1) Sikap peduli lingkungan mahasiswa perlu ditingkatkan lagi; 2) Minat berwirausaha mahasiswa sangat tinggi sehingga perlu difasilitasi melalui pembelajaran yang mengajak mahasiswa mempraktekkan keterampilan yang telah diajarkan. Hasil penelitian ini diharapkan dapat menjadi pijakan dalam bagaimana mengembangkan pembelajaran agar mendukung berkembangnya sikap peduli lingkungan dan minat berwirausaha mahasiswa.
\end{abstract}

Kata Kunci: Sikap peduli lingkungan, minat berwirausaha, model dan strategi pembelajaran

\section{PENDAHULUAN}

Pemanasan global dan meningkatnya kebutuhan pangan dunia adalah dua di antara isu lingkungan hidup yang menjadi karakteristik abad 21 (BNSP, 2010). Kenaikan populasi dunia yang semakin tak terkendali diyakini menjadi penyebab utamanya. Data dari Population Reference Bureau (2018) 
menunjukkan bahwa populasi pada tahun 2050 penduduk dunia akan mencapai angka 9,9 milyar. Laju pertumbuhan penduduk yang semakin pesat tersebut akan diiringi pula dengan semakin bertambahnya kebutuhan terhadap ruang, sandang, pangan, dan papan. Akibatnya kegiatan pembangunan pun akan semakin intensif dilakukan guna memenuhi kebutuhan hidup dan faktanya banyak ekosistem yang hilang sebagai dampak dari kegiatan tersebut. Permasalahan serupa juga ditemui di kota Palembang. Tingginya laju pembangunan yang terjadi dalam rangka memenuhi masyakat menyebabkan hilangnya sebagian ekosistem dan ruang terbuka yang ada. Akibatnya udara kota terasa semakin panas, banjir yang semakin sering terjadi, dan lain sebagainya. Adanya berbagai masalah tersebut mengindikasikan bahwa masih rendahnya tingkat kepedulian generasi sekarang terhadap lingkungan.

Berkaitan dengan hal tersebut, maka sikap peduli lingkungan menjadi salah satu hal yang penting untuk dikembangkan. Seseorang yang memiliki sikap peduli lingkungan cenderung akan merespon dengan baik hal-hal yang berkaitan dengan upaya baik menjaga, mencegah, maupun mengatasi masalah kerusakan lingkungan. Schaffrin (2013) yang menyatakan ada tiga karakteristik seseorang yang peduli terhadap lingkungan, antara lain: (1) menerima bahwa masalah lingkungan adalah suatu masalah yang serius; (2) setuju terhadap kebijakan lingkungan yang tetapkan; dan (3) menunjukkan kesediaan untuk mengambil tindakan pribadi untuk mengurangi terjadinya kerusakan lingkungan. Seseorang yang memiliki tiga karateristik tersebut cenderung akan selalu mengupayakan berbagai macam cara untuk menjaga lingkungan agar tidak rusak.

Selain sikap peduli lingkungan, hal lain yang penting dikembangkan di abad 21 adalah minat berwirausaha mahasiswa (Scott, 2015). Minat berwirausaha berkaitan dengan ketertarikan seseorang terhadap kegiatan yang kreatif dan inovatif untuk memenuhi kebutuhan hidupnya (Suryana, 2006). Ciri-ciri seorang yang memiliki minat berwirausaha, antara lain memiliki motivasi, tertarik, senang, dan tertarik berwirausaha (Mustofa, 2014). Alasan seseorang tertarik untuk berwirausaha adalah sebagai berikut: 1) Alasan keuangan, untuk mencari nafkah, kaya, pendapatan tambahan; 2) Alasan sosial, untuk memperoleh gengsi/status untuk dapat dikenal, dihormati dan bertemu orang banyakAlasan pelayanan, memberi pekerjaan pada 3) masyarakat; dan 4) Alasan pemenuhan diri, untuk menjadi mandiri, lebih produktif dan untuk menggunakan kemampuan pribadi (Suryana, 2006).

Sikap peduli lingkungan dan minat berwirausaha dapat dikembangkan melalui pembelajaran yang di dalamnya ada kegiatan pembekalan keterampilan dan kesempatan untuk mempraktikkan keterampilan tersebut. Mata kuliah Pengetahuan Lingkungan yang ada di Program Studi Pendidikan Biologi, Universitas Muhammadiyah Palembang diyakini dapat menjadi sarana yang tepat untuk meningkatkan sikap peduli lingkungan. Capaian Pembelajaran Mata Kuliah ini sangat mendukung berkembangnya kedua hal tersebut. Namun, data mengenai sikap peduli lingkungan dan minat berwirausaha mahasiswa setelah mengikuti perkuliahan ini belum ditemukan. Oleh karena itu, berdasarkan paparan yang telah diuraikan, maka perlu dilakukan analisis terhadap sikap peduli lingkungan dan minat kewirausahaan yang dimiliki mahasiswa mahasiswa yang mengikuti perkuliahan Pengetahuan Lingkungan.

\section{METODELOGI PENELITIAN}

Penelitian ini merupakan jenis penelitian deskriptif kualitatif. Penelitian ini berupaya untuk mendeskripsikan sikap peduli lingkungan dan minat kewirausahaan mahasiswa Program Studi Pendidikan Biologi Universitas Muhammadiyah Palembang. Subjek penelitian ini yaitu mahasiswa Program Studi Pendidikan Biologi Universitas Muhammadiyah Palembang semester VII Tahun 2016 yang mengontrak matakuliah Pengetahuan Lingkungan.

Data sikap peduli lingkungan dan minat kewirausahaan dikumpulkan melalui pemberian angket dan wawancara. Angket sikap peduli lingkungan yang digunakan adalah hasil pengembangan Saputri \& Djukri (2015). Sementara angket minat berwirausaha dimodifikasi dari Mustofa (2014). Kedua angket tersebut telah dinyatakan valid dan layak untuk digunakan. Data yang diperoleh kemudian di analisis secara deskriptif. 
HASIL DAN PEMBAHASAN

\section{Sikap Peduli Lingkungan}

Hasil analisis terhadap sikap peduli lingkungan disajikan pada Gambar 1.
Berdasarkan Gambar 1, diketahui diketahui sebesar $29,41 \%$ mahasiswa memiliki sikap peduli lingkungan dengan kategori sangat tinggi, 52,94\% berada pada kategori kategori tinggi, 17,64\% yang berada kategori sedang dan 2,94 yang berada pada kategori rendah

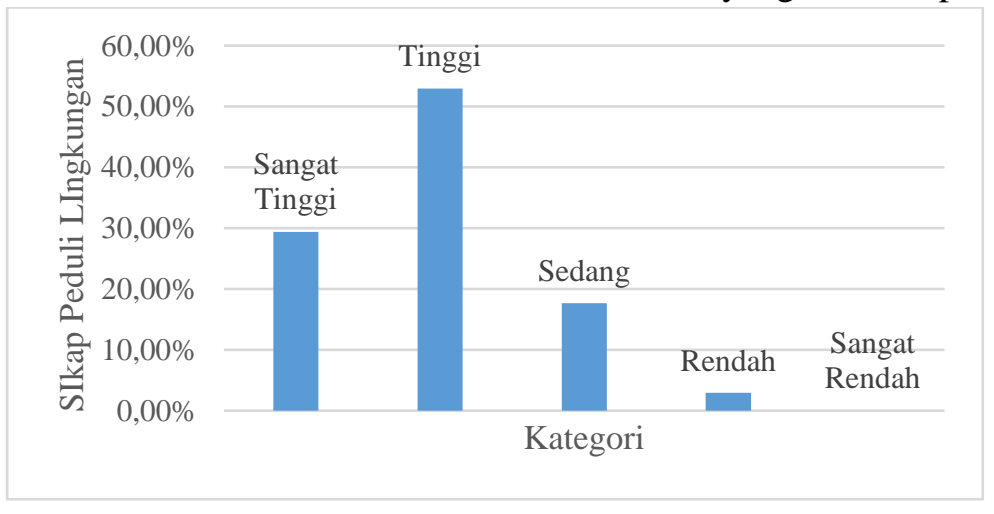

Gambar 1. Kategori Sikap Peduli Lingkungan Mahasiswa

Setelah terdapat data pada Gambar 1 di atas maka dilakukan wawancara kepada beberapa mahasiswa tentang praktik perkuliahan pengetahuan lingkungan selama ini. Berdasarkan hasil wawancara diketahui bahwa mereka senang dengan perkuliahan yang dilaksanakan selama ini. Selain ada kegiatan di dalam kelas untuk membahas konsep-konsep lingkungan, mahasiswa juga diajak untuk mengaplikasikan hasil perkulihan melalui kegiatan bersih-bersih kampus dan menanam tanaman di kebun biologi. Namun, ketika ditanya tentang penerapan sikap kepeduliannya di luar jam pelajaran ataupun di luar kampus beberapa beberapa mengaku terkadang masih suka membuang sampah sembarangan dan belum memisahkan sampah basah dan kering. Dengan demikian, sikap kepedulian mahasiswa terhadap lingkungan masih perlu ditingkatkan.

Temuan pada penelitian ini sejalan dengan Akkor \& Gündüz, (2018), Esa, (2010), Özden (2008), dan Wong (2003) yang menyatakan bahwa sikap peduli lingkungan mahasiswa masih perlu ditingkatkan lagi. Salah satu mata kuliah yang diyakini dapat memfasilitasi berkembangnya sikap tersebut adalah Pengetahuan Lingkungan. Hal ini karena sains memegang peran penting dalam menanamkan konsep dan berlatih memecahkan permasalahan lingkungan (Littledyke, 2008). Maka dari itu, perkuliahan Pengetahuan Lingkungan seharusnya tidak hanya berorientasi pada konsep-konsep saja tapi juga melibatkan lingkungan sekitar sebagai objek kajian alami. Adanya interaksi dengan lingkungan siswa tidak hanya dapat memahami dan menguasai konsep saja, tetapi juga dapat mengembangkan gagasangagasannya dalam mencari solusi terhadap permasalahan lingkungan yang ada. Özden (2008) menjelaskan bahwa hubungan sains, masyarakat, teknologi, dan lingkungan perlu dipertimbangkan dalam menentukan strategi pembelajaran yang akan diterapkan. Selain itu, sikap peduli lingkungan juga dapat ditingkatkan dengan mengintegrasikan pendidikan lingkungan ke dalam seluruh sistem pendidikan formal dan kurikulum sekolah dengan strategi pedagogis tertentu yang menjadikan lingkungan sebagai tempat atau bahan belajar (Hadzigeorgiou \& Skoumios, 2013).

Pembentukan sikap bukanlah hal yang mudah dan membutuhkan proses yang panjang. Dalam hal ini beberapa peneliti menyarakan pembentukan sikap sebaiknya dimulai dari semasa pra-sekolah sampai ke jenjang univesitas, baik formal dan informal (Esa, 2010; Littledyke, 2008; Özden, 2008). Oleh karena itu, dukungan dan komitmen yang kuat diperlukan dari berbagai pihak dalam rangka meningkatkan sikap peduli lingkungan mahasiswa, khususnya mahasiswa calon guru. Mahasiswa calon guru yang memiliki sikap serta perilaku yang positif terhadap lingkungan dapat menularkan hal 
positif tersebut pula kepada para siswanya kelak (Özden, 2008).

\section{Minat Berwirausaha}

Hasil analisis terhadap minat berwirausaha disajikan pada Gambar 1 .
Berdasarkan Gambar 1, dapat dilihat bahwa tidak ada yang tidak berminat untuk berwirausaha dengan $52,94 \%$ berada pada kategori sangat tinggi, 38,23\% berada pada kategori tinggi, dan $8,82 \%$ berada pada kategori rendah.

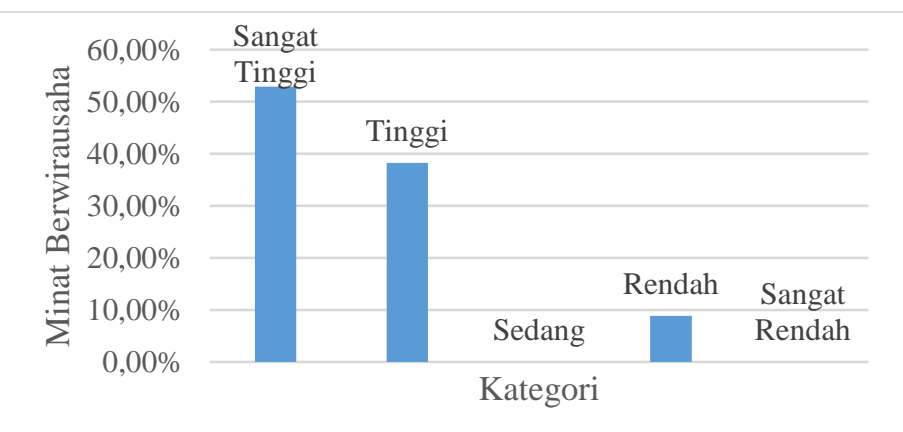

\section{Gambar 2. Kategori Minat Berwirausaha Mahasiswa}

Sejalan dengan data yang diperoleh dari pemberian angket, hasil wawancara terhadap sejumlah mahasiswa juga menunjukkan bahwa mereka sangat ingin menjadi wirausahawan, khususnya di bidang biologi. Mengingat sekarang tantangan untuk mendapatkan pekerjaan semakin hari semakin berat., sehingga berwirausaha dapat menjadi alternatif pekerjaan yang menjanjikan. Mahasiswa juga mengaku lebih senang jika dalam kuliah ada kegiatan praktiknya sehingga pengetahuan yang didapat menjadi lebih aplikatif dan bermanfaat. Dengan adanya minat berwirausaha diharapkan mahasiswa kelak dapat menciptakan lapangan pekerjaan bagi dirinya sendiri dan orang lain.

Minat berwirausaha dapat dikembangkan salah satunya melalui jalur pendidikan (Deba, Deba, Mallanti, Khata, \& Habibu, 2014; Din, Anuar, \& Usman, 2016; Tawil, Hassan, Ramlee, \& K-Batcha, 2015). Tawil et al., (2015) melaporkan bahwa $80 \%$ mahasiswa setuju bahwa praktek perkuliahan online bussiness simulation sangat mendukung adanya perolehan dasar keilmuan yang memadai dan meningkatkan minat mahasiswa untuk berwirausaha. Namun sayangnya, pada perkuliahan Pengetahuan Lingkungan yang ada di Program Studi Pendidikan Biologi Universitas Muhammadiyah Palembang nampaknya belum mendukung berkembangnya potensi tersebut. Hal ini karena ditemukan fakta bahwa setelah laporan kegiatan dikumpul maka berhenti pulalah praktik peduli lingkungan sebagaimana telah disebutkan. Kegiatan pembelajaran yang masih kurang bermakna bagi mahasiswa diduga menjadi penyebabnya.

Selain itu, upaya menumbuhkan minat berwirausaha melalui bidang sains masih awam. Hal ini sesuai dengan Deba, Deba, Mallanti, Khata, \& Habibu (2014) yang menemukan bahwa keterampilan berwirausaha mahasiswa jurusan teknik lebih tinggi daripada jurusan sains. Hal ini diduga karena adanya kesempatan mahasiswa jurusan teknik untuk mempraktekkan keterampilan yang dimiliki pada dunia kerja melalui kegiatan magang. Namun begitu, bukan berarti mahasiswa sains tidak bisa mengembangkan minat berwirausaha. Diperlukan suatu desain perkuliahan yang mampu menyempurnakan pola pembelajaran yang sudah ada dengan pembekalan keterampilan wirausaha tersebut. Perkuliahan harus mampu memfasilitasi mahasiswa untuk mempraktekkan teori yang diperolehnya pada dunia kerja (Din et al., 2016). Peran serta para pengambil kebijakan baik di pemerintahan maupun di lingkungan universitas sangat penting dalam hal ini (Deba et al., 2014; Din et al., 2016)

\section{KESIMPULAN}

Berdasarkan penelitian yang telah dilakukan dapat disimpulkan bahwa masih diperlukan upaya untuk memaksimalkan perkembangan sikap peduli lingkungan mahasiswa dan minat berwirasuaha mahasiswa. Perkuliahan Pengetahuan Lingkungan masih belum mendukung sepenuhnya perkembangan kedua hal tersebut. 
Dosen pengampu matakuliah harus berkomitmen untuk mengembangkan pembelajaran baik melalui model ataupun strategi pembelajaran tertentu sebagai solusi atas temuan tersebut.

\section{DAFTAR PUSTAKA}

Akkor, Ö., \& Gündüz, Ş. (2018). The study of university students' awareness and attitude towards environmental education in Northern Cyprus. Eurasia Journal of Mathematics, Science and Technology Education, 14(3), 1057-1062.

Badan Standar Nasional Pendidikan (BNSP). (2010). Paradigma Pendidikan Nasional Abad XXI. Jakarta: BNSP.

Deba. A, Deba, A. ., Mallanti, A., Khata, M., \& Habibu, M. A. (2014). Enhancing entrepreneurial skills of undergraduate science, vocational and technical education students through entrepreneurship education. Jounal of Technical Education and Training (JTET), 6(2), 38-55.

Din, B. H., Anuar, A. R., \& Usman, M. (2016). The Effectiveness of the Entrepreneurship Education Program in Upgrading Entrepreneurial Skills among Public University Students. Procedia Social and Behavioral Sciences, 224(August 2015), 117-123.

Esa, N. (2010). Environmental knowledge, attitude and practices of student teachers. International Research in Geographical and Environmental Education, 19(1), 3950.

Hadzigeorgiou, Y., \& Skoumios, M. (2013). The Development of Environmental Awareness through School Science: Problem and Possibilities. International Journal of Environmental \& Science Education, 8, 405-426.

Littledyke, M. (2008). Science education for environmental awareness: approaches to integrating cognitive and affective domains. Environmental Education Research, 14(1), 1-17.
Mustofa, M.A. (2014). Pengaruh Pengetahuan Kewirausahaan, Self Efficacy, dan Karakter Wirausaha Terhadap Minat Berwirausaha Pada Siswa Kelas XI SMK Negeri 1 Depok Kabupaten Sleman. Skripsi diterbitkan. Universitas Negeri Yogyakarta. (Online). (http://eprints.uny.ac.id/16081/)

Özden, M. (2008). Environmental awareness and attitudes of student teachers: An empirical research. International Research in Geographical and Environmental Education, 17(1), 40-55.

Schaffrin, A. (2013). No Measure without Concept: A Critical Review on the Conceptualization and Measuremen $t$ of Environmental Concern. International Review of Social Research, 1(3), 11-31.

Scott, L. C. (2015). Education Research and Foresight What Kind of Learning. (Online).

(https://unesdoc.unesco.org/ark:/48223/pf 0000242996)

Suryana (2006). Kewirausahaan Pedoman Praktis: Kiat dan Proses Menuju Suskes, Edisi Ketiga, Salemba: Jakarta.

Saputri, W., \& Djukri. (2015). Pengembangan Perangkat Pembelajaran Biologi dengan Model Problem Based LEarning (PBL) untuk Meningkatkan Penguasaan Konsep dan Sikap Peduli Lingkungan Siswa di SMA Negeri 1 Godean Yogyakarta. Tesis tidak diterbitkan. Universitas Negeri Yogyakarta.

Tawil, N. M., Hassan, R., Ramlee, S., \& KBatcha, Z. (2015). Enhancing entrepreneurship skill among university's students by online business simulation. Journal of Engineering Science and Technology, 10(Spec. Issue on 4th International Technical Conference (ITC) 2014), 71-80.

Wong, K. (2003). The Environmental Awareness of University Students in Beijing, China. Journal of Contemporary China, 12(36), 519-536. 